\title{
Prognostic Significance of Lymph Node Dissection Along the Upper-third-stomach in Patients With Lower-third Gastric Cancer
}

\author{
RYO SAITO, YOSHIHIKO KAWAGUCHI, HIDENORI AKAIKE, KENSUKE SHIRAISHI, \\ SUGURU MARUYAMA, HIROKI SHIMIZU, SHINJI FURUYA, NAOHIRO HOSOMURA, HIDETAKE AMEMIYA, \\ HIROMICHI KAWAIDA, MAKOTO SUDO, SHINGO INOUE, HIROSHI KONO and DAISUKE ICHIKAWA
}

First Department of Surgery, Faculty of Medicine, University of Yamanashi, Yamanashi, Japan

\begin{abstract}
Background/Aim: The extent of lymph node (LN) dissection is defined according to the type of gastrectomy regardless of tumor location in recent Japanese gastric cancer treatment guidelines. However, lymphatic flow from lowerthird stomach mainly drain to supra- and infra-pyloric nodes, as well as to partially lesser curvature nodes along the descending limb of the left gastric artery. In this study, we evaluated the prognostic impact of $L N$ dissection of right paracardial (No. 1) and left greater curvature (No. 4sb) nodes in gastric cancer of lower-third stomach $(L G C)$. Patients and Methods: A total of 239 patients with LGC who underwent distal gastrectomy at our hospital were retrospectively analyzed. The therapeutic value index (TVI) of each node was calculated by multiplying the incidence of LN metastasis by the 5-year survival rate of patients with metastasis to each nodal station. Results: The incidence of No. 1 LN metastasis was $4.5 \%$ (positive/negative; 5/110 cases, unknown or no description; 129 cases). The 5-year survival rate of patients with metastasis to the node was $0 \%$, and consequently the TVI of No. 1 LN station was "O". Similarly, the TVI of No. 4sb was found to be " 0 ". Conclusion: Survival benefit of dissection of No. 1 and No. 4sb LNs was presumed to be extremely low, suggesting that dissection of these two LNs could be omitted in LGC patients when undergoing distal gastrectomy.
\end{abstract}

Gastric cancer (GC) is one of the most aggressive malignancies and the fourth most lethal cancer worldwide (1). Recent advancements in diagnostic tools and the increased availability of medical examinations have resulted in the early detection of GC, particularly in the East Asian countries, such

Correspondence to: Daisuke Ichikawa, MD, First Department of Surgery, Faculty of Medicine, University of Yamanashi, 1110 Shimokato, Chuo, Yamanashi, 4093898 Japan. Tel/Fax: +81 552737390, e-mail: dichikawa@yamanashi.ac.jp

Key Words: Gastric cancer, lymph node dissection, distal gastrectomy. as Japan and Korea (2). Lymph node (LN) metastasis is a crucial prognostic factor in GC (3). The standard treatment strategy includes surgical resection of the primary lesion and dissection of the regional $\mathrm{LN}$, even in clinically node-negative cases $(4,5)$. Therefore, the precise extent and level of $\mathrm{LN}$ dissection are the main concerns of gastric surgeons.

The most recent Japanese Gastric Cancer Treatment Guidelines (5) define the extent of LN dissection according to the type of gastrectomy and also suggests that the level of LN dissection (e.g., D1, D1+, or D2) should be modified based on the tumor depth and clinical status of LN metastasis. The guidelines equally define all perigastric node stations as first-tier LNs, which are the most susceptible to metastasis. Although the lymphatic tracts are generally accompanied by vessels, the lymphatic fluid rarely flows from the primary lesion to the distant nodes. In fact, tumor involvement of the nodes distant from the primary lesions, such as pericardiac LNs in cases of lower-third GC (LGCs) or peripyloric nodes in cases of upper-third GCs has never been observed $(6,7)$.

In this study, we investigated the frequency of metastasis at the right pericardiac (No. 1) and the left greater curvature (No. 4sb) LN stations and determined the correlation between metastasis and clinicopathological factors in patients with LGCs. Moreover, we evaluated the survival benefit of LN dissection for these nodes in patients with LGCs.

\section{Patients and Methods}

Patients. Patients with LGC who underwent distal gastrectomy and regional LN dissection in the University of Yamanashi hospital from January 2004 to May 2017 were recruited. Clinicopathological data of patients were prospectively registered in our database. Patients who underwent modified limited LN dissection, such as pyloruspreserving gastrectomy and simple gastrectomy for far-advanced GC with clinically apparent distant metastases, as well as those with remnant stomach GCs were excluded.

Classification of $L N$ station and range of $L N$ dissection. The classification of $\mathrm{LN}$ station and range of $\mathrm{LN}$ dissection was in accordance with the Japanese Classification of Gastric Cancer, 15th 
Edition (8), and Gastric Cancer Treatment Guidelines 2018 (5), respectively. Briefly, No. $1 \mathrm{LN}$ station is defined as the region along the upper branch of the left gastric artery and the right side of the cardia; No. 4sb station is defined as the region along the left gastroepiploic artery. Although these LNs belong to the upper-third stomach, according to the guidelines, they should be dissected during distal gastrectomy for GC. The frequencies of metastasis are expressed as ratio of the pathologically positive nodes to the retrieved nodes.

Therapeutic value index of $L N$ dissection. We determined the therapeutic value index (TVI) of each LN station to evaluate the survival benefits of lymphadenectomy. TVI was calculated for each station individually as the ratio of $\mathrm{LN}$ metastasis $(\%) \times 5$-year survival rate in cases of $\mathrm{LN}$ metastasis $(\%) / 100$. We determined that LN dissection of stations with high TVI contributed to improved prognosis, whereas that of stations with low TVI showed no improvement in prognosis.

Statistical analyses. All continuous data are presented as mean \pm standard error or median value. Statistical analyses were conducted using chi-square test and Student's $t$-test. The 5-year survival rates were calculated using Kaplan-Meier method and statistically analyzed using the log-rank test. All statistical analyses were conducted with EZR (Saitama Medical Center, Jichi Medical University, Saitama, Japan), which is a graphical user interface for R (The R Foundation for Statistical Computing, Vienna, Austria) (9).

\section{Results}

Frequency of LN metastasis at No. 1 and No. 4sb stations in patients with LGC and correlation with clinicopathological features. Among the 721 patients with GC during the study period, 239 patients underwent distal gastrectomy with regional LN dissection. Table I shows patients' clinicopathological features. Twenty-two patients underwent gastrectomy after failed endoscopic treatments, such as mucosal resection or submucosal dissection, whereas 26 patients underwent laparoscopy. The frequencies of metastasis were $4.5 \%$ and $2.2 \%$ for No. 1 and No. 4sb LNs, respectively, which were very low compared with those for other perigastric LNs (Table IV).

Table II shows the correlation between No. 1 LN metastasis and clinicopathological features. The No. 1 LN metastasis significantly correlated with advanced $\mathrm{T}$ - and $\mathrm{N}$ stage of tumor ( $p=0.048$ and $p=0.003$, respectively), with lymphovascular invasion $(p=0.016)$ as well as with large size $(p=0.019)$, peritoneal lavage cytology (CY1) $(p=0.003)$, and non-curative operation $(p=0.045)$. Table III shows that No. $4 \mathrm{sb}$ LN metastasis significantly correlated lymphatic invasion $(p=0.016)$, and non-curative operation $(p=0.022)$. No. 1(+) and No. 4sb(+) cases had significantly greater total numbers of metastatic nodes than No. 1(-) and No. $4 \mathrm{sb}(-)$ cases $(p<0.001$ and $p=0.004$ respectively), which exhibited the extremely aggressive behavior of the tumors.

TVI of lymphadenectomy for each LN station. Table IV shows the TVI for each LN station. The 5-year survival rates of patients with and without LN metastasis at No. 1 station were $0 \%$ and $81.8 \%$, respectively. Therefore, the calculated TVI for LN dissection at the No. 1 station was 0 , and similarly TVI of No. 4sb station was also 0.

\section{Discussion}

Although the level of $\mathrm{LN}$ dissection (e.g., D1, D1+, or D2) is modified based on the tumor depth and clinical status of LN metastasis, the most recent Japanese Gastric Cancer Treatment Guidelines (5) define the extent of LN dissection only by the type of gastrectomy, regardless of tumor location. According to the guidelines, both No. 1 and No. 4sb nodes, which are distant from the primary tumors, should be dissected even for patients with LGC who undergo distal gastrectomy.

LN metastasis spreads along the lymphatic routes from the primary tumor. The peripheral lymphatic tissues are believed to be differentiated and germinated from the venous endothelial cells in the fetus (10); therefore, lymphatic networks and drainage routes are considered to be closely related to the venous system. Hence, lymphatic metastasis could initially develop to extend into the surrounding nodes, spread via the lymphatic routes along the venous return, and ultimately disseminate systematically through the body (11). With this perspective, lymphatic metastasis from primary LGC mainly spreads along the right gastric, right gastroepiploic, and left gastric vessels, which drain predominantly toward the gastropancreatic fold (12). Thus, lymphatic metastasis rarely develops in the nodes along the ascending branch of the left gastric vessels (No. 1) or the left gastroepiploic vessels (No. $4 \mathrm{sb}$ ), except when there is backflow due to lymphatic obstruction by bulky metastases (13). In fact, lymphatic metastasis has been rarely seen in the nodes along the upperthird of the stomach in patients with LGC. These findings prompted us to investigate the practical frequency of metastasis at No. 1 and No. 4sb stations and to evaluate the prognostic significance of LN dissection for these nodes.

The results of the present study clearly demonstrate that LN metastases at both No. 1 and No. 4sb stations are extremely rare and are correlated with far-advanced-stage cancer in patients with LGC. Prognostic analysis using TVI revealed that LN dissection for these nodes might provide prognostic information, but might not provide a survival benefit. To date, various studies on lymphatic flow around the stomach have been published. Shida et al. reported that lymphatic flow initially headed to the suprapylorus and infrapylorus or along the left gastric artery in LGC and that the sentinel LNs of LGC should mainly be No. 6, No. 5, and No. 7 (14). Another study suggested that there was almost no metastasis apart from that in the neighboring LNs in the regional LN stations, particularly in early GC (15). Therefore, limited gastrectomies, such as segmental gastrectomy or local resection, have been performed sometimes with sampling of adjacent LNs, based on the concept of sentinel node 
Table I. Clinicopathological features of patients with gastric cancer of lower-third stomach.

\begin{tabular}{|c|c|}
\hline Factor. & Number (\%) \\
\hline $\mathrm{n}$ & 239 \\
\hline Age (years)* & $69.1 \pm 11.0$ \\
\hline \multicolumn{2}{|l|}{ Gender } \\
\hline Male & $167(69.9)$ \\
\hline Female & $72(30.1)$ \\
\hline Tumor size $(\mathrm{mm})^{*}$ & $38.1 \pm 22.3$ \\
\hline \multicolumn{2}{|l|}{$\mathrm{T}$ factor } \\
\hline 1 & $154(64.4)$ \\
\hline $2-4$ & $85(35.6)$ \\
\hline \multicolumn{2}{|l|}{ LN metastasis } \\
\hline Absent & $159(66.5)$ \\
\hline Present & $80(33.5)$ \\
\hline \multicolumn{2}{|l|}{ Stage } \\
\hline I & $165(69.0)$ \\
\hline II-IV & $74(31.0)$ \\
\hline \multicolumn{2}{|l|}{ Lymphatic invasion } \\
\hline Absent & $123(51.5)$ \\
\hline Present & $116(48.5)$ \\
\hline \multicolumn{2}{|l|}{ Venous invasion } \\
\hline Absent & $147(61.5)$ \\
\hline Present & $92(38.5)$ \\
\hline \multicolumn{2}{|l|}{ Histopathological type } \\
\hline Differentiated & $134(56.1)$ \\
\hline Undifferentiated & $105(43.9)$ \\
\hline \multicolumn{2}{|l|}{ Macroscopic type } \\
\hline Localized & $64(26.8)$ \\
\hline Diffuse & $175(73.2)$ \\
\hline \multicolumn{2}{|l|}{$\mathrm{CY}$} \\
\hline CYO & $85(35.6)$ \\
\hline CY1 & $9(3.8)$ \\
\hline CYX & $145(60.7)$ \\
\hline \multicolumn{2}{|l|}{ Number of } \\
\hline LN dissection (median) & $26(0-97)$ \\
\hline LN metastasis (median) & $0(0-32)$ \\
\hline LN metastasis (mean) & 1.86 \\
\hline \multicolumn{2}{|l|}{ Level of LN dissection (D) } \\
\hline$\leq \mathrm{D} 1+$ & $141(59.0)$ \\
\hline$\geq \mathrm{D} 2$ & $98(41.0)$ \\
\hline \multicolumn{2}{|l|}{ Peritoneal dissemination } \\
\hline Absent & $235(98.3)$ \\
\hline Present & $4(1.7)$ \\
\hline \multicolumn{2}{|l|}{ Residual tumor } \\
\hline Absent (R0/1) & $238(99.6)$ \\
\hline Present (R2) & $1(0.4)$ \\
\hline
\end{tabular}

*Mean \pm standard deviation. LN, Lymph node; CY, peritoneal lavage cytology.

as experimental trials $(16,17)$. However, the cases of false negative results in sentinel node navigation surgery cannot be ignored (18). These findings indicate that at least regional LN dissection should be performed in current clinical practice.

The present results may indicate that $\mathrm{LN}$ dissection in this area can be omitted in patients with LGC, with the following two possible advantages: (i) simplified surgical procedures
Table II. Correlation between clinicopathological features and status of No.1 lymph node metastasis.

\begin{tabular}{|c|c|c|c|}
\hline Factor & $\begin{array}{c}\text { No.1(+) } \\
\text { n }(\%)\end{array}$ & $\begin{array}{c}\text { No.1(-) } \\
\text { n (\%) }\end{array}$ & $p$-Value \\
\hline $\mathrm{n}$ & 5 & 105 & \\
\hline \multicolumn{4}{|l|}{ Age (years) } \\
\hline$<65$ & $2(40.0)$ & $30(28.6)$ & \multirow[t]{2}{*}{0.627} \\
\hline$\geq 65$ & $3(60.0)$ & $75(71.4)$ & \\
\hline \multicolumn{4}{|l|}{ Gender } \\
\hline Male & $4(80.0)$ & $73(69.5)$ & \multirow[t]{2}{*}{1} \\
\hline Female & $1(20.0)$ & $32(30.5)$ & \\
\hline \multicolumn{4}{|l|}{ Tumor size (mm) } \\
\hline$<35$ & $0(0.0)$ & $59(56.2)$ & \multirow[t]{2}{*}{0.019} \\
\hline$\geq 35$ & $5(100.0)$ & $46(43.8)$ & \\
\hline \multicolumn{4}{|l|}{$\mathrm{T}$ factor } \\
\hline 1 & $1(20.0)$ & $71(67.6)$ & \multirow[t]{2}{*}{0.048} \\
\hline $2-4$ & $4(80.0)$ & $34(32.4)$ & \\
\hline \multicolumn{4}{|l|}{ LN metastasis } \\
\hline Absent & $0(0.0)$ & $75(71.4)$ & \multirow[t]{2}{*}{0.003} \\
\hline Present & $5(100.0)$ & $30(28.6)$ & \\
\hline \multicolumn{4}{|l|}{ Stage } \\
\hline I & $0(0.0)$ & $78(74.3)$ & \multirow[t]{2}{*}{0.002} \\
\hline II-IV & $5(100.0)$ & $27(25.7)$ & \\
\hline \multicolumn{4}{|l|}{ Lymphatic invasion } \\
\hline Absent & $0(0.0)$ & $61(58.1)$ & \multirow[t]{2}{*}{0.016} \\
\hline Present & $5(100.0)$ & $44(41.9)$ & \\
\hline \multicolumn{4}{|l|}{ Venous invasion } \\
\hline Absent & $0(0.0)$ & $61(58.1)$ & \multirow[t]{2}{*}{0.016} \\
\hline Present & $5(100.0)$ & $44(41.9)$ & \\
\hline \multicolumn{4}{|c|}{ Histopathological type } \\
\hline Differentiated & $2(40.0)$ & $57(54.3)$ & \multirow[t]{2}{*}{0.661} \\
\hline Undifferentiated & $3(60.0)$ & $48(45.7)$ & \\
\hline \multicolumn{4}{|l|}{ Macroscopic type } \\
\hline Localized & $0(0.0)$ & $36(34.3)$ & \multirow[t]{2}{*}{0.17} \\
\hline Diffuse & $5(100.0)$ & $69(65.7)$ & \\
\hline \multicolumn{4}{|l|}{$\mathrm{CY}$} \\
\hline CY0 & $2(40.0)$ & $37(97.4)$ & \multirow[t]{2}{*}{0.003} \\
\hline CY1 & $3(60.0)$ & $1(2.6)$ & \\
\hline \multicolumn{4}{|l|}{ Number of } \\
\hline LN dissection ${ }^{1}$ & $27(23-97)$ & $30(4-75)$ & 0.58 \\
\hline LN metastasis ${ }^{1}$ & $12(6-32)$ & $0(0-12)$ & $<0.001$ \\
\hline $\mathrm{LN}_{\text {metastasis }}^{2}$ & 17.0 & 0.93 & $<0.001$ \\
\hline \multicolumn{4}{|c|}{ Level of LN dissection (D) } \\
\hline$\leq \mathrm{D} 1+$ & $1(20.0)$ & $57(54.3)$ & \multirow[t]{2}{*}{0.187} \\
\hline$\geq \mathrm{D} 2$ & $4(80.0)$ & $48(45.7)$ & \\
\hline Residual tumor & & & \\
\hline Absent (R0/1) & $4(80.0)$ & $105(100.0)$ & 0.045 \\
\hline Present (R2) & $1(20.0)$ & $0(0.0)$ & \\
\hline
\end{tabular}

${ }^{1}$ Data presented as median (range). ${ }^{2}$ Data presented as mean. Statistically significant $p$-values are shown in bold. LN, Lymph node; CY, peritoneal lavage cytology.

with a short operative duration and small volume of blood loss and (ii) potentially decreased incidence of intraoperative and postoperative complications. For example, the most recent Japanese Gastric Cancer Treatment Guidelines (5) list laparoscopic gastrectomy as a surgical option for patients with 
Table III. Correlation between clinicopathological features and status of No.4sb lymph node metastasis.

\begin{tabular}{|c|c|c|c|}
\hline Factor & No.4sb(+) & No.4sb(-) & $p$-Value \\
\hline $\mathrm{n}$ & 2 & 91 & \\
\hline \multicolumn{4}{|l|}{ Age (years) } \\
\hline$<65$ & $2(40.0)$ & $30(28.6)$ & \multirow[t]{2}{*}{0.627} \\
\hline$\geq 65$ & $3(60.0)$ & 75 (71.4) & \\
\hline \multicolumn{4}{|l|}{ Gender } \\
\hline Male & $1(50.0)$ & $66(72.5)$ & \multirow[t]{2}{*}{0.483} \\
\hline Female & $1(50.0)$ & $25(27.5)$ & \\
\hline \multicolumn{4}{|l|}{ Tumor size (mm) } \\
\hline$<35$ & $0(0.0)$ & $51(56.0)$ & \multirow[t]{2}{*}{0.201} \\
\hline$\geq 35$ & $2(100.0)$ & $40(44.0)$ & \\
\hline \multicolumn{4}{|l|}{$\mathrm{T}$ factor } \\
\hline 1 & $0(0.0)$ & $64(70.3)$ & \multirow[t]{2}{*}{0.095} \\
\hline $2-4$ & $2(100.0)$ & $27(29.7)$ & \\
\hline \multicolumn{4}{|l|}{ LN metastasis } \\
\hline Absent & $0(0.0)$ & $66(72.5)$ & \multirow[t]{2}{*}{0.082} \\
\hline Present & $2(100.0)$ & $25(27.5)$ & \\
\hline \multicolumn{4}{|l|}{ Stage } \\
\hline I & $0(0.0)$ & $70(76.9)$ & \multirow[t]{2}{*}{0.059} \\
\hline II-IV & $2(100.0)$ & $21(23.1)$ & \\
\hline \multicolumn{4}{|l|}{ Lymphatic invasion } \\
\hline Absent & $0(0.0)$ & $61(58.1)$ & \multirow[t]{2}{*}{0.016} \\
\hline Present & $5(100.0)$ & $44(41.9)$ & \\
\hline \multicolumn{4}{|l|}{ Venous invasion } \\
\hline Absent & $0(0.0)$ & $60(65.9)$ & \multirow[t]{2}{*}{0.123} \\
\hline Present & $2(100.0)$ & $31(34.1)$ & \\
\hline \multicolumn{4}{|c|}{ Histopathological type } \\
\hline Differentiated & $2(100.0)$ & $52(57.1)$ & \multirow[t]{2}{*}{0.508} \\
\hline Undifferentiated & $0(0.0)$ & $39(42.9)$ & \\
\hline \multicolumn{4}{|l|}{ Macroscopic type } \\
\hline Localized & $1(50.0)$ & $22(24.2)$ & \multirow[t]{2}{*}{0.435} \\
\hline Diffuse & $1(50.0)$ & $69(75.8)$ & \\
\hline \multicolumn{4}{|l|}{$\mathrm{CY}$} \\
\hline CY0 & $2(100.0)$ & $28(93.3)$ & \multirow[t]{2}{*}{1} \\
\hline CY1 & $0(0.0)$ & $2(6.7)$ & \\
\hline \multicolumn{4}{|l|}{ Number of } \\
\hline LN dissection ${ }^{1}$ & $26(24-28)$ & $28(4-73)$ & 0.791 \\
\hline LN metastasis ${ }^{1}$ & $12(12-12)$ & $0(0-32)$ & 0.004 \\
\hline LN metastasis2 & 12.00 & 1.18 & $<0.001$ \\
\hline \multicolumn{4}{|c|}{ Level of LN dissection (D) } \\
\hline$\leq \mathrm{D} 1+$ & $1(50.0)$ & $55(60.4)$ & \multirow[t]{2}{*}{1} \\
\hline$\geq \mathrm{D} 2$ & $1(50.0)$ & $36(39.6)$ & \\
\hline Residual tumor & & & \\
\hline Absent (R0/1) & $1(50.0)$ & $91(100.0)$ & 0.022 \\
\hline Present (R2) & $1(50.0)$ & $0(0.0)$ & \\
\hline
\end{tabular}

${ }^{1}$ Data presented as median (range). ${ }^{2}$ Data presented as mean. Statistically significant $p$-values are shown in bold. LN, Lymph node; CY, peritoneal lavage cytology.

GC, and it is indeed a widely practiced procedure (19). The operative duration of laparoscopy has been reported to be longer than that of laparotomy $(20,21)$ and can be shortened by omitting ineffective lymphadenectomy. Another more important advantage is the possible preservation of remnant stomach function. The vagal nerves run along the lesser curvature and supply some anterior gastric branches from the
Table IV. Therapeutic value index (TVI) of each lymph node (LN) station.

\begin{tabular}{lcccl}
\hline $\begin{array}{l}\text { LN } \\
\text { station }\end{array}$ & $\begin{array}{c}\text { LN metastasis } \\
\text { (positive/total) }\end{array}$ & $\begin{array}{c}\text { Frequency of } \\
\text { LN metastasis (\%) }\end{array}$ & $\begin{array}{c}\text { 5-year } \\
\text { survival rate (\%) }\end{array}$ & TVI \\
\hline 1 & $5 / 110$ & 4.5 & 0 & 0 \\
3 & $37 / 216$ & 17.1 & 38.8 & 6.65 \\
$4 \mathrm{sb}$ & $2 / 93$ & 2.2 & 0 & 0 \\
$4 \mathrm{~d}$ & $34 / 224$ & 15.2 & 27.2 & 4.2 \\
5 & $15 / 108$ & 13.9 & 37.8 & 5.25 \\
6 & $49 / 203$ & 24.1 & 38.8 & 9.37 \\
$7,8,9$ & $35 / 220$ & 15.9 & 31.8 & 5.06 \\
$11 \mathrm{p}$ & $1 / 52$ & 1.9 & 0 & 0 \\
$12 \mathrm{a}$ & $2 / 42$ & 4.8 & 0 & 0 \\
$14 \mathrm{v}$ & $3 / 58$ & 5.2 & 0 & 0 \\
\hline
\end{tabular}

anterior vagal trunk and some posterior gastric branches from the posterior celiac vagal trunk (22). Intraoperative injury to these nerves and branches, which are involved in stomach peristalsis and secretion $(23,24)$, results in peristaltic dyskinesia and secretory dysfunction of the remnant stomach, thereby causing deterioration of organ function postoperatively (25). Therefore, omission of an unnecessary LN dissection may improve the postoperative function of remnant stomach digestion and/or absorption, although prospective clinical trials should be conducted to prove this hypothesis.

There are several limitations in this study. First, the number of cases examined was very small. Second, there may be a selection bias for systematic LN dissection, such as cases diagnosed as clinically node positive at No. 1 and/or No. 4sb stations. Therefore, further prospective accumulation of the cases and investigation are necessary to ascertain the frequency of the LN metastases and to evaluate the survival benefit of LN dissection.

\section{Conclusion}

The frequencies of LN metastases at No. 1 and No. 4sb stations were rare in patients with LGC, and moreover, the survival benefit of $\mathrm{LN}$ dissection was presumed to be extremely low in these patients. In conclusion, $\mathrm{LN}$ dissection along the upper-third-stomach could be omitted in patients with lower-third-gastric cancer undergoing distal gastrectomy, in order to preserve remnant gastric function.

\section{Conflicts of Interest}

The Authors declare no conflict of interests.

\section{Authors' contributions}

Ryo Saito performed the majority of experiments and wrote the manuscript. Daisuke Ichikawa designed the research and helped to draft the manuscript. All authors reviewed the manuscript. 


\section{References}

1 Bray F, Ferlay J, Soerjomataram I, Siegel RL, Torre LA and Jemal A: Global cancer statistics 2018: Globocan estimates of incidence and mortality worldwide for 36 cancers in 185 countries. CA Cancer J Clin 68(6): 394-424, 2018. PMID: 30207593, DOI: 10.3322/caac.21492

2 Zhang X, Li M, Chen S, Hu J, Guo Q, Liu R, Zheng H, Jin Z, Yuan Y, Xi Y and Hua B: Endoscopic screening in asian countries is associated with reduced gastric cancer mortality: A meta-analysis and systematic review. Gastroenterology 155(2): 347-354.e349, 2018. PMID: 29723507, DOI: 10.1053/j.gastro.2018.04.026

3 Li X, Liu Y, Cao B, Liu B, Bai T, Li X, Mei L and Che X: Metastatic lymph node ratio and prognosis of gastric cancer at different pt stages. Hepatogastroenterology 62(138): 507-511, 2015. PMID: 25916091

4 Degiuli M, De Manzoni G, Di Leo A, D’Ugo D, Galasso E, Marrelli D, Petrioli R, Polom K, Roviello F, Santullo F and Morino M: Gastric cancer: Current status of lymph node dissection. World J Gastroenterol 22(10): 2875-2893, 2016. PMID: 26973384, DOI: 10.3748/wjg.v22.i10.2875

5 Japanese Gastric Cancer Association, Gastric Cancer Treatment Guidelines 2018, Kanehara, Tokyo, 2018.

6 Haruta S, Shinohara H, Hosogi H, Ohkura Y, Kobayashi N, Mizuno A, Okamura R, Ueno M, Sakai Y and Udagawa H: Proximal gastrectomy with exclusion of no. $3 \mathrm{~b}$ lesser curvature lymph node dissection could be indicated for patients with advanced upper-third gastric cancer. Gastric Cancer 20(3): 528535, 2017. PMID: 27379895, DOI: 10.1007/s10120-016-0624-2

7 Xu YY, Huang BJ, Sun Z, Lu C and Liu YP: Risk factors for lymph node metastasis and evaluation of reasonable surgery for early gastric cancer. World J Gastroenterol 13(38): 5133-5138, 2007. PMID: 17876881 .

8 Japanese Gastric Cancer Association. Japanese Classification of Gastric Cancer, Kanehara, Tokyo, 2017.

9 Kanda Y: Investigation of the freely available easy-to-use software 'EZR' for medical statistics. Bone Marrow Transplant 48(3): 452458, 2013. PMID: 23208313, DOI: 10.1038/bmt.2012.244

10 Tammela $\mathrm{T}$ and Alitalo K: Lymphangiogenesis: Molecular mechanisms and future promise. Cell 140(4): 460-476, 2010. PMID: 20178740, DOI: 10.1016/j.cell.2010.01.045

11 Karlsson MC, Gonzalez SF, Welin J and Fuxe J: Epithelialmesenchymal transition in cancer metastasis through the lymphatic system. Mol Oncol 11(7): 781-791, 2017. PMID: 28590032, DOI: $10.1002 / 1878-0261.12092$

12 Tokunaga M, Ohyama S, Hiki N, Fukunaga T, Yamada K, Sano $\mathrm{T}$ and Yamaguchi $\mathrm{T}$ : Investigation of the lymphatic stream of the stomach in gastric cancer with solitary lymph node metastasis. World J Surg 33(6): 1235-1239, 2009. PMID: 19288280, DOI: $10.1007 / \mathrm{s} 00268-009-9985-6$

13 Karaman S and Detmar M: Mechanisms of lymphatic metastasis. J Clin Invest 124(3): 922-928, 2014. PMID: 24590277, DOI: 10.1172/JCI71606

14 Shida A, Mitsumori N, Fujioka S, Takano Y, Fujisaki M, Hashizume R, Takahashi N, Ishibashi Y and Yanaga K: Sentinel node navigation surgery for early gastric cancer: Analysis of factors which affect direction of lymphatic drainage. World J Surg 42(3): 766-772, 2018. PMID: 28920152, DOI: 10.1007/ s00268-017-4226-X

15 Kitagawa Y, Takeuchi H, Takagi Y, Natsugoe S, Terashima M, Murakami N, Fujimura T, Tsujimoto H, Hayashi H, Yoshimizu
N, Takagane A, Mohri Y, Nabeshima K, Uenosono Y, Kinami S, Sakamoto J, Morita S, Aikou T, Miwa K and Kitajima M: Sentinel node mapping for gastric cancer: A prospective multicenter trial in japan. J Clin Oncol 31(29): 3704-3710, 2013. PMID: 24019550, DOI: 10.1200/JCO.2013.50.3789

16 Kim TH, Kong SH, Park JH, Son YG, Huh YJ, Suh YS, Lee HJ and Yang HK: Assessment of the completeness of lymph node dissection using near-infrared imaging with indocyanine green in laparoscopic gastrectomy for gastric cancer. J Gastric Cancer 18(2): 161-171, 2018. PMID: 29984066, DOI: 10.5230/ jgc.2018.18.e19

17 Shida A, Mitsumori N, Nimura H, Takano Y, Iwasaki T, Fujisaki $\mathrm{M}$, Takahashi $\mathrm{N}$ and Yanaga K: Prediction of lymph node metastasis and sentinel node navigation surgery for patients with early-stage gastric cancer. World J Gastroenterol 22(33): 74317439, 2016. PMID: 27672266, DOI: 10.3748/wjg.v22.i33.7431

18 Miyashiro I, Hiratsuka M, Sasako M, Sano T, Mizusawa J, Nakamura K, Nashimoto A, Tsuburaya A and Fukushima N: High false-negative proportion of intraoperative histological examination as a serious problem for clinical application of sentinel node biopsy for early gastric cancer: Final results of the japan clinical oncology group multicenter trial JCOG0302. Gastric Cancer 17(2): 316-323, 2014. PMID: 23933782, DOI: 10.1007/s 10120-013-0285-3

19 Caruso S, Patriti A, Roviello F, De Franco L, Franceschini F, Coratti A and Ceccarelli G: Laparoscopic and robot-assisted gastrectomy for gastric cancer: Current considerations. World J Gastroenterol 22(25): 5694-5717, 2016. PMID: 27433084, DOI: 10.3748/wjg.v22.i25.5694

20 Cui M, Li Z, Xing J, Yao Z, Liu M, Chen L, Zhang C, Yang H, Zhang N, Tan F, Jiang B, Di J, Wang Z, Ji J and Su X: A prospective randomized clinical trial comparing D2 dissection in laparoscopic and open gastrectomy for gastric cancer. Med Oncol 32(10): 241, 2015. PMID: 26350550, DOI: 10.1007/ s12032-015-0680-1

21 Haverkamp L, Weijs TJ, van der Sluis PC, van der Tweel I, Ruurda JP and van Hillegersberg R: Laparoscopic total gastrectomy versus open total gastrectomy for cancer: A systematic review and meta-analysis. Surg Endosc 27(5): 15091520, 2013. PMID: 23263644, DOI: 10.1007/s00464-012-2661-1

22 Baccaro LM, Lucas CN, Zandomeni MR, Selvino MV and Albanese EF: Anatomy of the anterior vagus nerve: An anatomic description and its application in surgery. Anat Physiol 3(2): 26, 2013. DOI: $10.4172 / 2161-0940.1000121$

23 Edin R, Lundberg J, Terenius L, Dahlstrom A, Hokfelt T, Kewenter J and Ahlman H: Evidence for vagal enkephalinergic neural control of the feline pylorus and stomach. Gastroenterology 78(3): 492-497, 1980. PMID: 6985879.

24 Jordan PH Jr. and Thornby J: Twenty years after parietal cell vagotomy or selective vagotomy antrectomy for treatment of duodenal ulcer. Final report. Ann Surg 220(3): 283-293; discussion 293-286, 1994. PMID: 8092897.

25 Nomura E and Okajima K: Function-preserving gastrectomy for gastric cancer in japan. World J Gastroenterol 22(26): 58885895, 2016. PMID: 27468183, DOI: 10.3748/wjg.v22.i26.5888

Received January 26, 2019

Revised February 10, 2019

Accepted February 11, 2019 